\title{
An Alternating Copolymer of a Tetrapeptide and a Tetrathiophene Prepared by a Click Reaction: A Study of the Synthesis and Assembly Behavior
}

\author{
Ruiying Gong, Zongxia Guo, Fei Li, Yubao Song, Youbing $\mathrm{Mu}$, Ming Li, \\ Xiaobo Wan*
}

Alternating copolymers of an oligopeptide $\left(\mathrm{N}_{3}-\mathrm{GVGV}-\mathrm{N}_{3}\right.$, where G: glycine; V: valine) and an oligothiophene (5,5'-bis(ethynyl)-3,3'-dioctyltetrathiophene) are prepared by click chemistry. The experimental results discover that these copolymers exhibit strong molecular-weightdependent self-assembly behaviors. The copolymer P1 with the lowest weight-average molecular weight $\left(\bar{M}_{\mathrm{w}}=7400 \mathrm{~g} \mathrm{~mol}^{-1}\right)$, assembles into well-ordered fibrous nanostructures. P3 $\left(\bar{M}_{\mathrm{w}}=16980 \mathrm{~g} \mathrm{~mol}^{-1}\right)$ assembles into nanoballs. P2, which has the medium $\bar{M}_{\mathrm{w}}$ between P1 and P3, $\left(\bar{M}_{\mathrm{w}}=14800 \mathrm{~g} \mathrm{~mol}^{-1}\right)$, exhibits more-complicated self-assembly behaviors, more like a transition state between the other two. All of the results suggest the selfassembly ability of these oligopeptide segments might be the major reason for the nano-structure evolution.

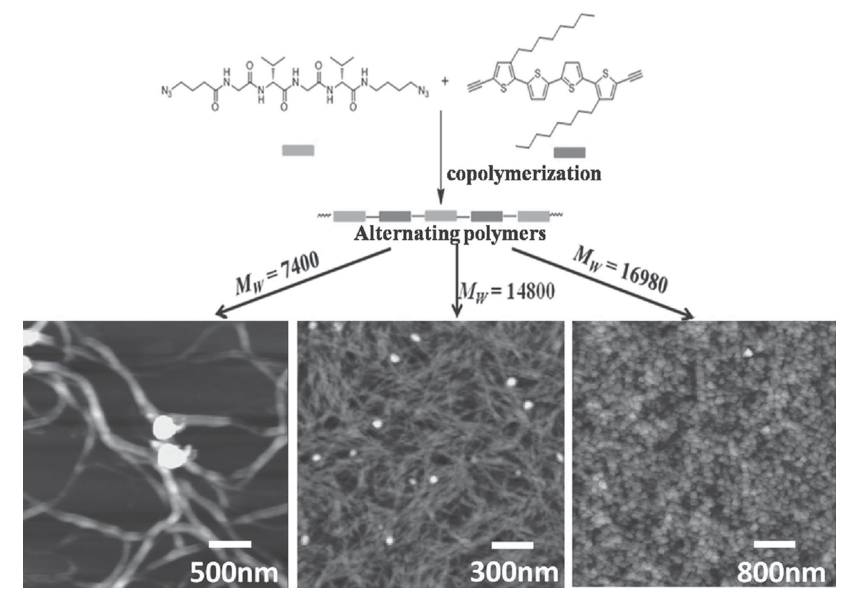

\section{Introduction}

Self-assembly is one of most promising approaches to prepare nanostructural materials. Since short peptide segments could produce various self-assembled structures,

Dr. R. Gong, Dr. Z. Guo, F. Li, Y. Mu, Prof. X. Wan

CAS Key Laboratory of Bio-based Materials, Oingdao Institute of Bioenergy and Bioprocess Technology, Chinese Academy of Sciences, Qingdao 266101, P. R. China

E-mail: wanxb@qibebt.ac.cn

Y. Song, Prof. M. Li

Department of Chemistry, Qingdao University of Science and Technology, 53 Zhengzhou Road, Oingdao, Shandong Province 266042, P. R. China

they were used to adjust the nanostructure of conventional synthetic polymers and $\pi$-conjugated oligomers. ${ }^{[1-8]}$ Ever since the first example of an oligothiophene directly conjugated with a $\beta$-sheet-forming peptide was reported by Bäuerle and coworkers ${ }^{[4]}$ in 2004; oligothiophene and its derivatives, as one type of stable semiconductors, ${ }^{[9-11]}$ were subjected to extensive modification with oligopeptides to achieve better nanostructure control by several research groups (Bäuerle, Klok, Tovar, Stupp, Börner, to name a few) in the past decade. ${ }^{[6-8,12-17]}$ Many results from these researchers confirmed that well-structured nanofibrils consisting of $\beta$-sheets were formed in these conjugate aggregates, and the theoretical study suggested that the peptide segment of the hybrid governed the selfassembly via hydrogen bonding and the oligothiophene 
contributed to the stability of the suprastructure through the $\pi-\pi$ stacking. Although significant progress had been made in the design and self-assembly studies of these short hybrid oligomers, the extension of such nanostructural control into polymer area is rarely reported. The self-assembly behavior of a triblock copolymer of fluorene and glutamic acid was studied. ${ }^{[18,19]}$ The nanostructural control of polypeptide with oligothiophene side chains and polythiophene with oligopeptide side chains was also reported. ${ }^{[20,21]}$ However, little attention has been paid to the design and studies of the self-assembly behavior of alternating copolymers of oligopeptides and oligothiophenes or other $\pi$-conjugated oligomers. One of the reasons might be that the synthesis of alternating copolymers of oligopeptides and oligothiophene can be very challenging, since even oligopeptide-oligothiophene conjugates (which can be considered as the smallest repeating units in the alternating copolymer) are not readily soluble in most organic solvents, which implies that the synthesis of a longer backbone would be unfeasible. Here arises a question: how will the alternating copolymers of oligothiophene and oligopeptides self-assemble: will they behave similarly to those oligomers or quite differently? This question remains largely illusive to material chemists. It becomes interesting to develop an alternating copolymer consisting of a conjugating oligopeptide and oligothiophene to have a deeper insight into their selfassembly behavior.

Here, we report a study of the synthesis and selfassembly behavior of an alternating copolymer of tetrathiophene and a tetrapeptide. Both monomers were rationally designed to guarantee the solubility of the resulting copolymer. Copper (I)-catalyzed azidealkyne cycloaddition (CuAAC) ("click chemistry") was employed as the effective technique for copolymerization. Three alternating polymers with different molecular weights were prepared by an elaborate control of the polymerization conditions. The self-assembly behavior of these copolymers was extensively studied by scanning electron microscopy (SEM), atomic force microscopy (AFM), X-ray diffraction (XRD), and UV-vis and Fourier transform IR (FTIR) spectroscopy. A strong molecularweight-dependent self-assembly behavior of these copolymers was revealed.

\section{Experimental Section}

\subsection{Click Copolymerization}

The synthesis of alternating poly(tetrapeptide/tetrathiophene) is shown in Scheme 1. A typical preparation method is described below:

To a stirred solution of tetrapeptide 1 (76 $\mathrm{mg}, 0.14 \mathrm{mmol})$ in dry DMF (10 mL), was added 2 ( $85 \mathrm{mg}, 0.14 \mathrm{mmol}), 2,2^{\prime}$-bipyridine (218.7 mg, $1.4 \mathrm{mmol}), \mathrm{CuI}(27 \mathrm{mg}, 1.4 \mathrm{mmol}$ ), and ascorbic acid (124 mg, $0.7 \mathrm{mmol}$ ) at $80^{\circ} \mathrm{C}$ under nitrogen. The reaction mixture was then stirred at $80^{\circ} \mathrm{C}$ for $6 \mathrm{~d}$. The reaction was monitored by thin-layer chromatography (TLC). After the reaction finished, the mixture was pipetted into $200 \mathrm{~mL}$ of $\mathrm{Et}_{2} \mathrm{O}$ and the resulting brown powder was filtered and dried under reduced pressure to afford the desired polymer in $98 \%$ yield (157.8 $\mathrm{mg}$ ). Characterization data of alternating copolymer: IR $\left(\mathrm{KBr}, \mathrm{cm}^{-1}\right): 3292(-\mathrm{NH}), 3066$ $\left(-\mathrm{C}_{4} \mathrm{H}_{4} \mathrm{~S}\right), 2925\left(-\mathrm{CH}_{2}\right), 2100(-\mathrm{C} \equiv \mathrm{H}), 1647$ (-CONH), 1631 $(-\mathrm{NH}), 1540(-\mathrm{NH}), 1442\left(-\mathrm{COCH}_{2}\right) .{ }^{1} \mathrm{H}$ NMR $(600 \mathrm{MHz}$, DMSO$\left.d_{6}\right) \delta$ 0.89-1.0 $\left(-\mathrm{CH}_{3}\right), 1.3\left(-\mathrm{CH}_{2}\right), 1.7\left(-\mathrm{CH}_{2}\right), 1.9-2.1\left(-\mathrm{CH}_{2}\right.$, $-\mathrm{CH}), 2.5-2.9\left(-\mathrm{CH}_{2}\right), 3.3\left(-\mathrm{CH}_{2}\right), 4.1-4.4\left(-\mathrm{CH}_{2}\right), 7.3(-\mathrm{CH}), 7.7-$ $8.2(-\mathrm{NH}), 8.5(-\mathrm{CH})$.

\subsection{Pulsed-Gradient Spin-Echo (PGSE) Nuclear Magnetic Resonance (NMR) Experiments}

PGSE-NMR experiments were performed on a Bruker AVANCE AOS600 NMR spectrometer. Two oligomers with known molecular weights of tetrapeptide-tetrathiophene-tetrapeptide (TPT) and tetrathiophene-tetrapeptide-tetrathiophene (PTP) ${ }^{[22]}$ were used as standards for diffusion coefficient $(D)$ tests (the structures of PTP and TPT are shown in Scheme S1, Supporting Information). The molecular weight of the polymer was deduced by comparing its $D$ value with those of the oligomers. Details of the calculation were performed according to a reported procedure. ${ }^{[23-25]}$

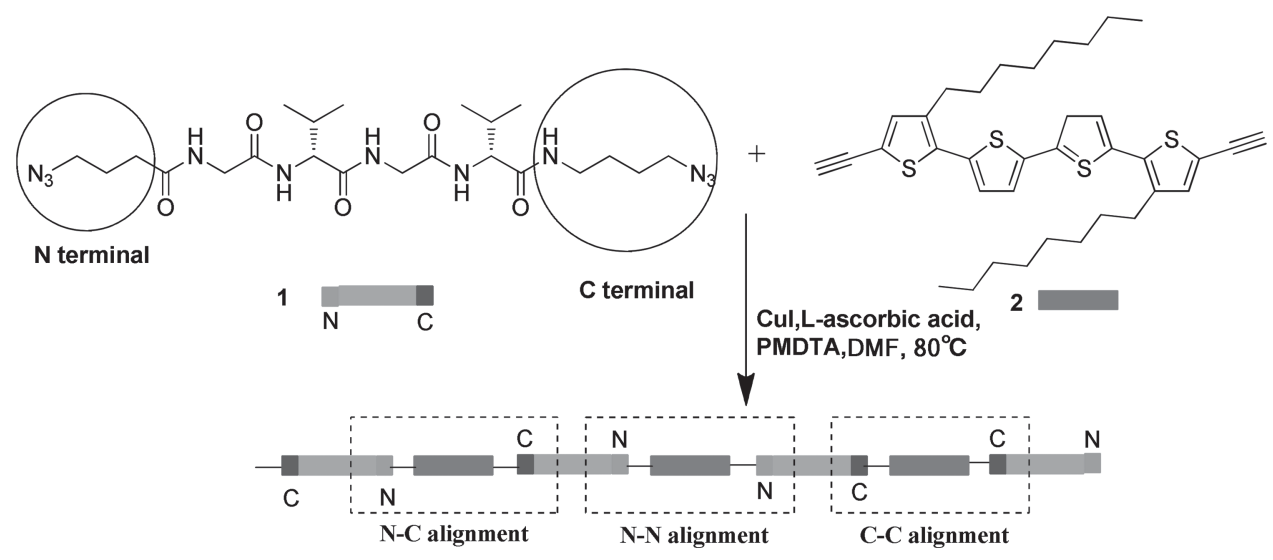

Scheme 1. Synthesis route of alternating poly(tetrapeptide-tetrathiophene).

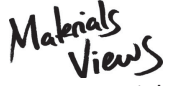

www.MaterialsViews.com
Macromol. Chem. Phys. 2014, 215, 906-914 (c) 2014 WILEY-VCH Verlag GmbH \& Co. KGaA, Weinheim 
www.mcp-journal.de

Table 1. Synthetic conditions of polymers $\mathbf{P}_{\mathbf{1}}, \mathbf{P}_{\mathbf{2}}$, and $\mathbf{P}_{\mathbf{3}}$.

\begin{tabular}{lcccccc}
\hline Entry & $\begin{array}{c}\text { Tetrapeptide } \\
{[\mathbf{m m o l}]}\end{array}$ & $\begin{array}{c}\text { Tetrathiophene } \\
{[\mathbf{m m o l}]}\end{array}$ & $\begin{array}{c}\text { CuI } \\
\text { [mmol] }\end{array}$ & $\begin{array}{c}\text { L-ascorbic acid } \\
{[\mathbf{m m o l}]}\end{array}$ & $\begin{array}{c}\text { Ligand }{ }^{\mathrm{a})} \\
{[\mathbf{m m o l}]}\end{array}$ & $\begin{array}{c}\text { Reaction time } \\
{[\mathrm{h}]}\end{array}$ \\
\hline P1 & 1 & 1 & 0.05 & 0.05 & 0 & 24 \\
P2 & 1 & 1 & 10 & 8 & $17.2 / \mathrm{bidy}$ & 96 \\
P3 & 1 & 1 & 10 & 8 & $17.2 /$ PMDTA & 96
\end{tabular}

a)bidy: bipyridine; PMDTA: pentamethyldiethylenetriamine.

\subsection{Characterization}

FTIR spectroscopy analysis was carried out on Nicolet 6700 FTIR spectrometer. The samples were spread on $\mathrm{KBr}$ discs for the FTIR spectroscopy measurements. AFM was performed on an Agilent5400 instrument using tapping mode. SEM was performed on a Hitachi S-4800 instrument with an accelerating voltage of $2.5 \mathrm{kV}$. The samples for AFM, SEM, and XRD characterization were prepared as follows: the freshly prepared copolymer solutions were cast on freshly cleaved mica and dried under reduced pressure for $15 \mathrm{~h}$ before the tests. XRD studies were performed on a Bruker D8 Advance X-ray diffractometer. The instrument was equipped with a $1.5 \mathrm{~kW} \mathrm{Cu} \mathrm{K}_{\alpha}$ tube, which emits X-ray radiation at a wavelength of $0.154 \mathrm{~nm}$. UV-vis spectra of the alternating polymers were recorded using a Cary 50 UV-vis spectrometer.

\section{Results and Discussion}

\subsection{Synthesis of the Alternating Copolymers}

In our previous study, an oligopeptide $\mathrm{N}_{3}$-GVGV-OMe (G: glycine; V: valine) was synthesized. The tetrapeptide was readily soluble in most organic solvents and showed a strong tendency to assemble into antiparallel $\beta$-sheets when a poor solvent was added. ${ }^{[26]}$ Based on these results, another tetrapeptide $\mathrm{N}_{3}-$ GVGV-N $\mathrm{N}_{3}$ (compound 1; see Scheme S2, Supporting Information) was prepared with both terminals modified with an azide moiety. The oligothiophene comonomer $\mathbf{2}$ was carefully designed (see Scheme S3, Supporting Information) using two octyl side chains on the terminal thiophene rings to increase its solubility and two clickable alkyne terminals for polymerization. The corresponding alternating polymers were prepared by click reaction between tetrapeptide $\mathbf{1}$ and tetrathiophene $\mathbf{2}$ in nearly quantitative yield. We were aware that the alternating copolymers synthesized via this way would not be region-regular, and three possible alignment directions of the oligopeptide segments in the backbone (Scheme 1) were anticipated, since $\mathrm{N}_{3}-\mathrm{GVGV}-\mathrm{N}_{3}$ did not possess a symmetric structure.

Three polymers P1, P2, and P3 with different molecular weights were prepared by screening different catalysts loadings, CuI-stabilizers, and their dosages. The detailed reaction conditions are shown in Table 1 . In all cases, CuI was used as the promoter. In entry 1 , catalytic amount of CuI was used, while in the other two entries, 10 equiv. of $\mathrm{CuI}$ was used. Excess $\mathrm{CuI}$ and longer reaction time were necessary to produce copolymer with higher molecular weight. Different ligands were also screened (entry 1, no ligand; entry 2, bipyridine; entry 3, pentamethyldiethylenetriamine (PMDTA)) to achieve high weight-average molecular weight $\left(\bar{M}_{\mathrm{w}}\right)$. In all cases, brown powders were obtained. The obtained polymers were not soluble in common organic solvents, but were soluble in highly polar organic solvents such as DMF and DMSO. The three copolymers showed different solubility in DMF, as shown in Table 2, which implies that the molecular weights of these three copolymers are different.

The alternating copolymers were characterized by the ${ }^{1} \mathrm{H}$ NMR technique. Different from the oligomers such as tetrapeptide-tetrathiophene-tetrapeptide (TPT) and tetrathiophene-tetrapeptide-tetrathiophene (PTP), all the copolymers showed much broader ${ }^{1} \mathrm{H}$ NMR signals

Table 2. Self-diffusion coefficients $D$, molecular weights $\bar{M}_{w}$, solubilities, and monomer ratios of alternating polymers $\mathbf{P}_{\mathbf{1}}, \mathbf{P}_{\mathbf{2}}, \mathbf{P}_{\mathbf{3}}$.

\begin{tabular}{|c|c|c|c|c|c|}
\hline Polymer & $\begin{array}{c}\bar{M}_{\mathrm{w}}^{\mathrm{a})} \\
{\left[\mathrm{g} \mathrm{mol}^{-1}\right]}\end{array}$ & $\begin{array}{l}\mathrm{D} \times 10^{-10} \\
{\left[\mathrm{~m}^{2} \mathrm{~s}^{-1}\right]}\end{array}$ & $\begin{array}{c}\bar{M}_{\mathrm{w}}^{\mathrm{b})} \\
{\left[\mathrm{g} \mathrm{mol}^{-1}\right]}\end{array}$ & $\begin{array}{c}\text { Solubility (at } 25^{\circ} \mathrm{C} \text { ) } \\
{\left[\mathrm{mg} \mathrm{mL}^{-1}\right]}\end{array}$ & $\begin{array}{l}\text { Incorporation } \\
\text { ratio for } \\
\text { tetrapeptide/ } \\
\text { tetrathiophene }\end{array}$ \\
\hline P1 & 7380 & 2.76 & 7400 & 204 & $7 / 6$ \\
\hline P2 & 14810 & 1.16 & 14800 & 115 & $13 / 12$ \\
\hline P3 & 17100 & 0.98 & 16980 & 90 & $16 / 15$ \\
\hline
\end{tabular}

a) Calculated by $1 \mathrm{H}$ NMR; ${ }^{\text {b) }}$ Determined by PGSE. 
(see Figure S1 and S2, Supporting Information), which is a typical feature for polymers. Here, we took P2 as a typical example to determine the assignations of all the peaks. The ${ }^{1} \mathrm{H}$ NMR spectrum of $\mathbf{P 2}$ is shown in Figure 1. The peak at $8.5 \mathrm{ppm}$ is assigned to the proton of the triazole ring. The peaks at 7.7-8.3 and 7.1-7.4 ppm are corresponding to $-\mathrm{NH}-$ from tetrapeptides and $-\mathrm{CH}-$ from the tetrathiophene ring, respectively. The chemical shifts 1-4.5 from the other protons are almost invariable compared with that of the monomeric tetrapeptide and tetrathiophene (see Figures S3 and S4, Supporting Information). Since the peaks overlap together, it is difficult to precisely assign the corresponding proton. The signal from the alkyne terminals was barely seen in the NMR, indicating a nearly complete incorporation of monomers into the polymer.

Although the obtained polymers were soluble in DMF and DMSO, their molecular weights and polydispersities were very difficult to be determined, due to their strong tendency to self-assemble. We attempted to determine them by size-exclusion chromatography (SEC) using either hexafluoro-2-propanol or $\mathrm{DMF} / \mathrm{LiBr}$ as the eluents. However, extremely large $\bar{M}_{\mathrm{w}}$ (over $100 \mathrm{kDa}$ ) was obtained, which is questionable. The problem remained unsolved even if we tried to destroy the assembly structure by carrying out the SEC test at elevated temperature $\left(60^{\circ} \mathrm{C}\right)$. Matrix-assisted laser desorption ionization time of flight mass spectrometry (MALDI-TOF MS) was also tried. Two matrices, alfa-cyano-4-hydroxycinnamic acid (ACCA) and 2,5-dihydroxybenzoic acid (2,5-DHB), were screened, but unfortunately, no valuable data were obtained. DLS tests did not give reasonable result either. The $\bar{M}_{\mathrm{w}}$ was then estimated indirectly via pulsed gradient spin-echo nuclear magnetic resonance (PGSE-NMR) techniques (Table 2). PGSE can be used to estimate the molecular weight of a polymer by the measurement of its molecular self-diffusion coefficient. ${ }^{[25]}$ The molecular weight of a polymer and its molecular self-diffusion coefficient $D$ are correlated: a lower self-diffusion coefficient $D$ indicates a higher molecular weight of the polymer, as described in the following equation:

$$
D=K M_{\mathrm{w}}^{-\alpha}
$$

where $K$ and $\alpha$ are scaling parameters that depend on the polymer structure as well as the experimental conditions. Typically, they are obtained by analyzing a series of monodisperse polymer standards under a given set of experimental conditions. Two oligomers tetrapeptidetetrathiophene-tetrapeptide (TPT) and tetrathiophenetetrapeptide-tetrathiophene (PTP) at hand were provided as the standards to roughly estimate the relative molecular weight of the polymers. In addition, we also roughly deduced the molecular weight of the three polymers from the ratio of $-\mathrm{CH}_{3}$ peak integrals of tetrapeptide to that of tetrathiophene in ${ }^{1} \mathrm{H}$ NMR (Table 2), which was in good agreement with the results from PGSE data. Among the three copolymers, the molecular weight of $\mathbf{P 1}$ is the lowest, and that of P3 is the highest. This result also fits well with their solubility in DMF: P1 is the most soluble (240 mg $\left.\mathrm{mL}^{-1}\right)$, while $\mathbf{P 3}$ is the least soluble $\left(90 \mathrm{mg} \mathrm{mL}^{-1}\right)$.

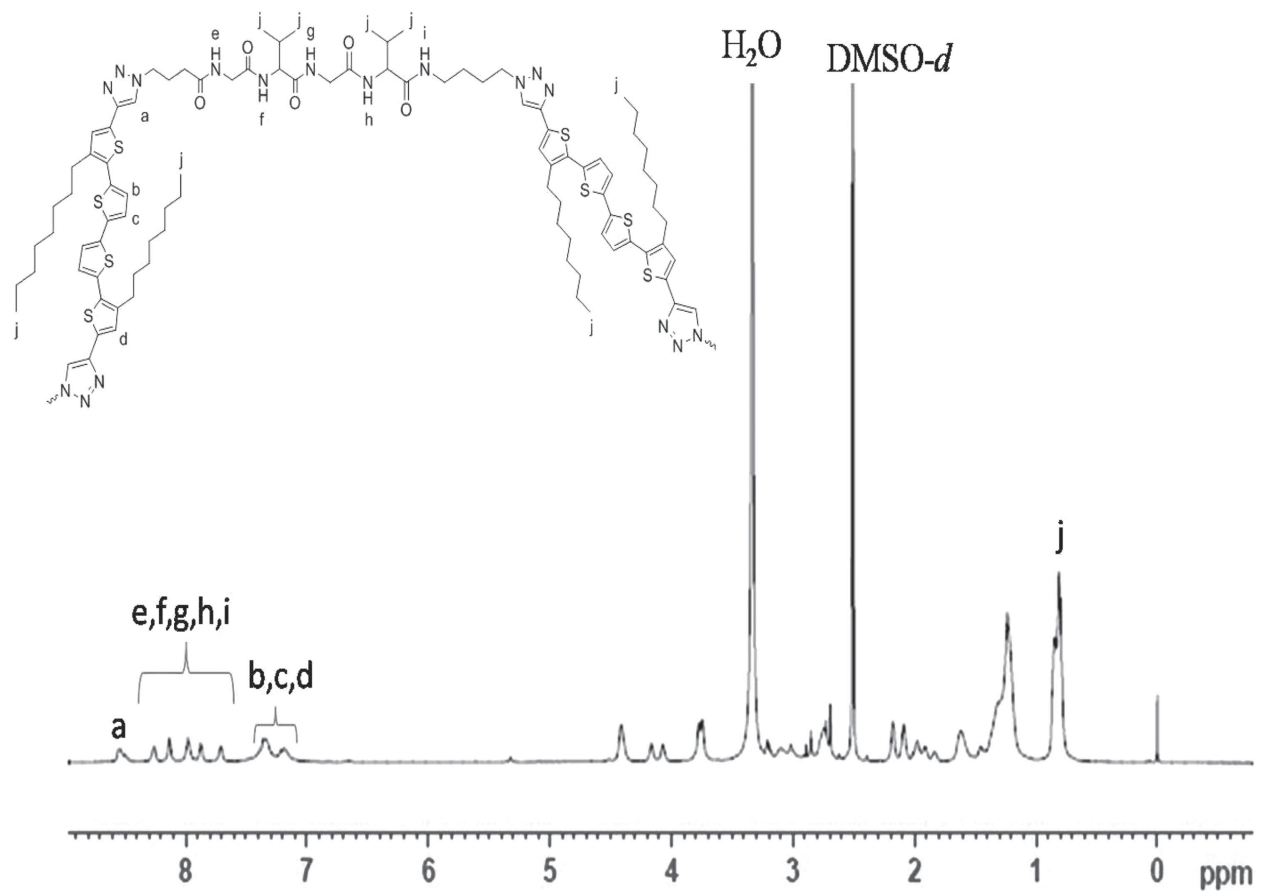

Figure 1. ${ }^{1} \mathrm{H}$ NMR spectra of $\mathbf{P} \mathbf{2}$.

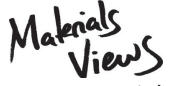

www.MaterialsViews.com 


\subsection{Self-Assembly Behaviors of P1, P2, and P3 on Mica Surface}

Strong self-assembly of alternating copolymers was already observed in our attempts to characterize them by SEC technique, and it was further investigated using SEM and AFM techniques. Very interestingly, a molecular weight-dependent nanoassembly evolution was observed. P1, the copolymer with the lowest molecular weight, when cast onto a mica surface from DMF solution and dried under vacuum, exhibited a fibrous structure, with the fiber width around $30 \mathrm{~nm}$ (Figure 2a). Long fibrils (several to tens of micrometers) were clearly observed, and the higher-level hierarchical structures composed of at least two or more twisted filaments could be seen. Further aggregation occurred when the sample was stored for $5 \mathrm{~d}$ and a more compact stacking was observed (Figure 2d). For P3, the copolymer with the highest molecular weight, to our surprise, no nanofibers were observed; instead, relatively even-sized spherical balls with a diameter around $20 \mathrm{~nm}$ were obtained (Figure 2c). These nanoballs would also aggregate with prolonged storage time (Figure 2f). For P2, the copolymer with the medium molecular weight (but closer to the high-molecular-weight region), although fibril-like structure was also observed (Figure 2b), but it was much shorter compared with that of P1. When subjected to prolonged storage time, the aggregation of P2 led to a nanostructure (as shown in Figure 2e) more similar to that of P3. Overall, P1 easily assembles into fibril network, and P3 assembles into nanoballs, while the nanostructure of $\mathbf{P 2}$ is more complicated, more like a transition state between the other two.

\subsection{X-Ray Diffraction Analysis}

$\mathrm{X}$-ray diffraction (XRD) is a rapid analytical technique primarily used for phase identification of a crystalline material. Figure 3 shows the diffraction patterns for P1, P2, and P3. An obvious diffraction pattern was observed for P1 and P2, which indicates that they are semicrystalline. For P3, only a very wide diffraction peak from 22 to $24^{\circ}$ was observed, suggesting that P3 was an amorphous
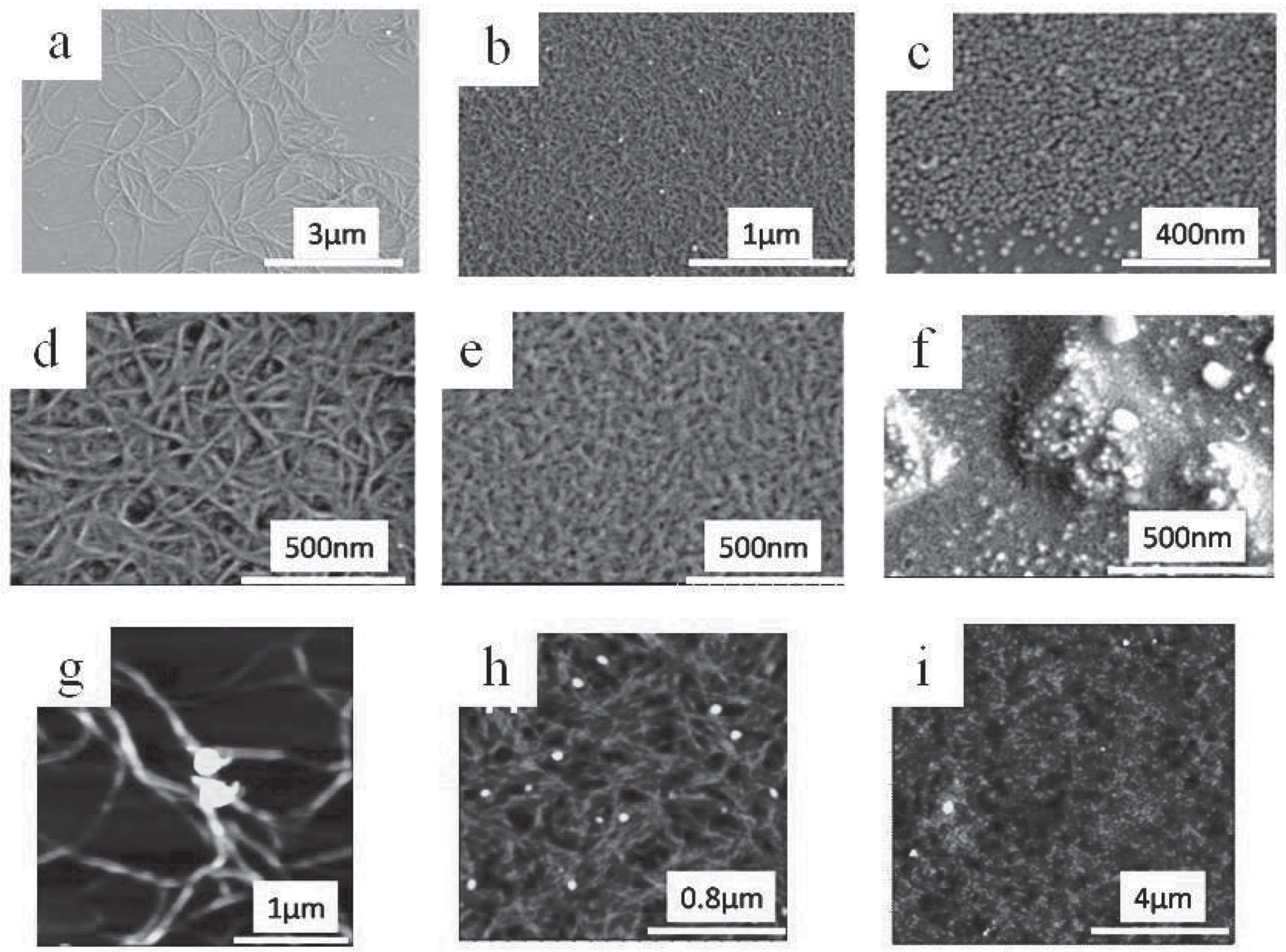

Figure 2. a-f) SEM images and g-i) AFM images of the solution-cast thin films of $\mathbf{P}_{\mathbf{1}}, \mathbf{P}_{\mathbf{2}}$, and $\mathbf{P}_{\mathbf{3}}$. Concentration of $\mathrm{DMF}$ solution: $1 \mathrm{mg} \mathrm{mL}^{-1}$. Images $(d-f)$ were the samples of a-c stored for $5 \mathrm{~d}$ for full aggregate, respectively. 


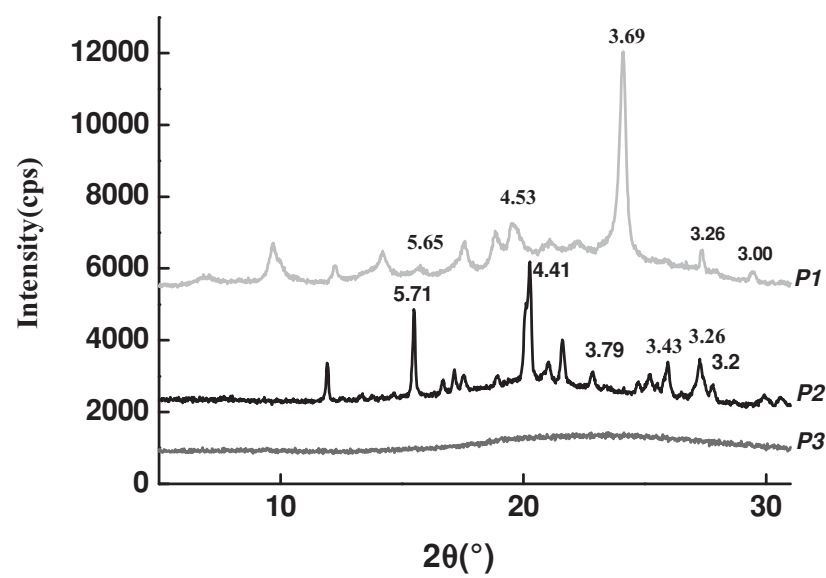

Figure 3. X-ray diffraction spectra of $\mathbf{P}_{1}, \mathbf{P}_{2}$, and $\mathbf{P}_{\mathbf{3}}$.

polymer. The diffraction pattern of P1 shows peaks with $\mathrm{d}$ spacing of $5.65,4.53$, and $3.69 \AA$, which is in accordance with $\beta$-sheet formation. ${ }^{[3,27]}$ The peaks at 3.69 and 5.65 $\AA$ are assigned to the intersheet spacing: $3.69 \AA$ for the glycyl-glycyl juxtaposed faces and $5.65 \AA$ for the methylmethyl juxtaposed faces, respectively. ${ }^{[28]}$ The peak at 4.53 $\AA$ is assigned to the interchain spacing within a hydrogenbonded sheet. For P2, these peaks shifted to 5.71, 4.41, and $3.79 \AA$, which might be due to the difference of the assembled nanostructure. Furthermore, some weak peaks at the regions of $20-30^{\circ}$ of $\mathbf{P 1}$ and $\mathbf{P 2}$ are assigned to the oriented assembly of the tetrathiophene segments. These results revealed that $\mathbf{P 1}$ and $\mathbf{P 2}$ could form a locally well-ordered nanostructure due to the self-assembly of tetrapeptide segments, which was in a good agreement with the results from SEM and AFM: P1 and P2 could form 1D fibrous nanostructure, while $\mathbf{P 3}$ could not.

\subsection{UV-vis Absorption Spectra in Solution and Films}

UV-vis absorption is sensitive to the inter-chromophore distance and orientation, which has been widely used to study their $\pi-\pi$ stacking. The absorption spectra of P1, P2, and P3 in dilute DMF solution and in film state are shown in Figure 4A. The absorption maxima for P1, P2, and P3 in DMF solution are slightly different. With the increase of the molecular weight, the absorption maxima blueshifted from 417 (P1) to $412 \mathrm{~nm}$ (P2) and to $408 \mathrm{~nm}$ (P3). The blue-shift indicates that the $\pi-\pi$ interaction between oligothiophene segments was slightly weakened with the increase of molecular weight.

This phenomenon became more obvious in film-state UV-vis spectra (Figure 4B). The spectrum of the film of P1 showed a significant red-shift $(18 \mathrm{~nm}$, from 417 to $435 \mathrm{~nm}$ ) compared with that in the solution, which was associated with the ordered stacking of tetrathiophene segment into J-type aggregate. ${ }^{[29]}$ However, the maxima absorption band of the film for polymer P2 ( $\approx 414 \mathrm{~nm})$ and P3 $(\approx 410 \mathrm{~nm})$ showed only a slight redshift compared with that in solution, indicating that the $\pi-\pi$ interaction between oligothiophene segments in polymer with high molecular weight in film state was not stronger than that in solution state.

\subsection{FTIR Spectra}

The absorptions of the amide $\mathrm{A}$ and I and II regions in FTIR spectra were indicative of peptide's secondary structures such as $\alpha$-helices and $\beta$-sheets, ${ }^{[27]}$ FTIR spectroscopy analysis was performed to give an insight into the assembly behavior of tetrapeptides segment in the alternating copolymers. Only the FTIR spectra of P1, P2, and P3 in their powder state (shown in Figure S5, Supporting Information) were compared, since the background peaks of the solvent seriously overlapped with that of polymers and could not be easily removed in the solution state. The strong absorption at $\approx 2100 \mathrm{~cm}^{-1}$ in the spectrum of $\mathbf{P 1}$ was assigned to the residue azide group in the copolymer, which is barely seen in the spectrum of $\mathbf{P 2}$ and $\mathbf{P 3}$, which also indicates that the molecular weight of P1 is much smaller than that of P2 and P3. The enlarged amide I and amide II regions are shown in Figure 5. The copolymer P1 shows an obvious absorption at $\approx 1631 \mathrm{~cm}^{-1}$ and a weak absorption at $\approx 1695 \mathrm{~cm}^{-1}$, which indicates the formation of an ordered nanostructure comprising the anti-parallel $\beta$-sheets from the oligopeptide segments. The copolymers P2 and P3 show relatively weak absorptions in these regions, indicating that the peptides segments in $\mathbf{P 2}$ and $\mathbf{P 3}$ are not packed as well as that in P1. Generally, $\beta$-sheet reflects intermolecular assembly, and $\alpha$-helix reflects intramolecular assembly. ${ }^{[30]}$ It was reasonable to postulate that the backbone of polymer with small molecular weight unfolded more easily, which was beneficial for the intermolecular assembly to form $\beta$-sheets. With the increase of the molecular weight, this tendency became weaker, maybe due to stronger intramolecular

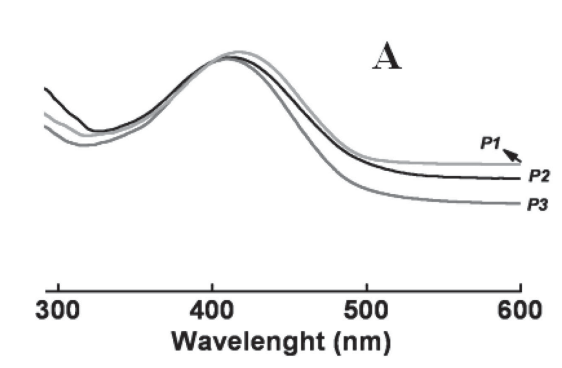

Figure 4. UV absorption spectra of three copolymers: A) in dilute DMF solution $\left(0.125 \mathrm{mg} \mathrm{mL}^{-1}\right)$ and $B$ ) in film state cast from DMF solution $\left(2 \mathrm{mg} \mathrm{mL}^{-1}\right)$.

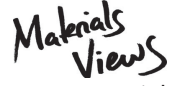

www.MaterialsViews.com
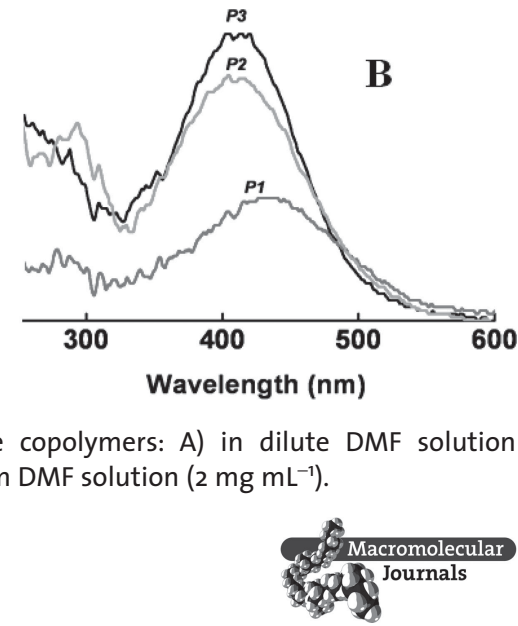

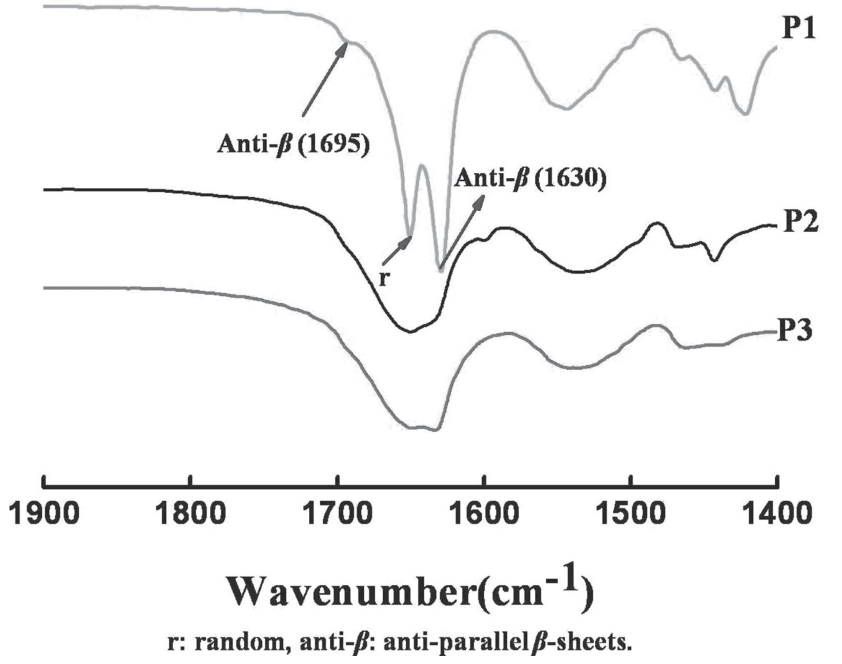

Figure 5. Amide I and II regions of the FTIR spectra of alternating polymers. Anti- $\beta$ : anti-parallel $\beta$-sheet; $r$ : random coil.

entanglement of the backbone, and the $\beta$-sheet formation between the tetrapeptide segments was largely hindered.

\subsection{Possible Explanation for Molecular Weight-Dependent Nanostructure Evolution}

The molecular weight-dependent nanostructure evolution of the oligopeptide-oligothiophene alternating polymer is very interesting and was not reported on other oligothio- phene-oligopeptide conjugates. The exact mechanism for this evolution at current stage is not known and might be very complicated; we speculated that one of the reasons lied in the different entanglement capability of backbones caused by the difference in molecular weight. The stack models for P1, P2, and P3 in solutions or in solid state were proposed in Figure 6. The reasons of a molecular weightdependent nanostructure evolution might be explained as: i) P1, the polymer with lowest molecular weight, might be solvated more easily to adopt a more extended conformation, and during the solvent evaporation, the anti-parallel $\beta$-sheets were formed via the H-bonding between the oligopeptide segments, which also assisted the assembly of oligothiophene segments via $\pi-\pi$ interaction as shown in Figure 6a; ii) P3, the copolymer with the highest molecular weight, could not be solvated well by the solvents (which is reflected by its low solubility in solution), and is prone to form more serious self-folding and self-entanglement (shown in Figure $6 \mathrm{c}$ ) due to the free-rotating alkyl spacers, which connect more repeating units, thus make intramolecular H-bonding occurs. Thus, the $\beta$-sheet formation ability between tetrapeptide segments and $\pi-\pi$ interaction between different molecular chains were both largely weakened. Consequently, no obvious $\beta$-sheet formation was observed for P3, as evidenced by FTIR spectroscopy, and also no strong intramolecular $\pi-\pi$ interaction was observed, as evidenced by the similarity of its UV-vis spectra both in solution and

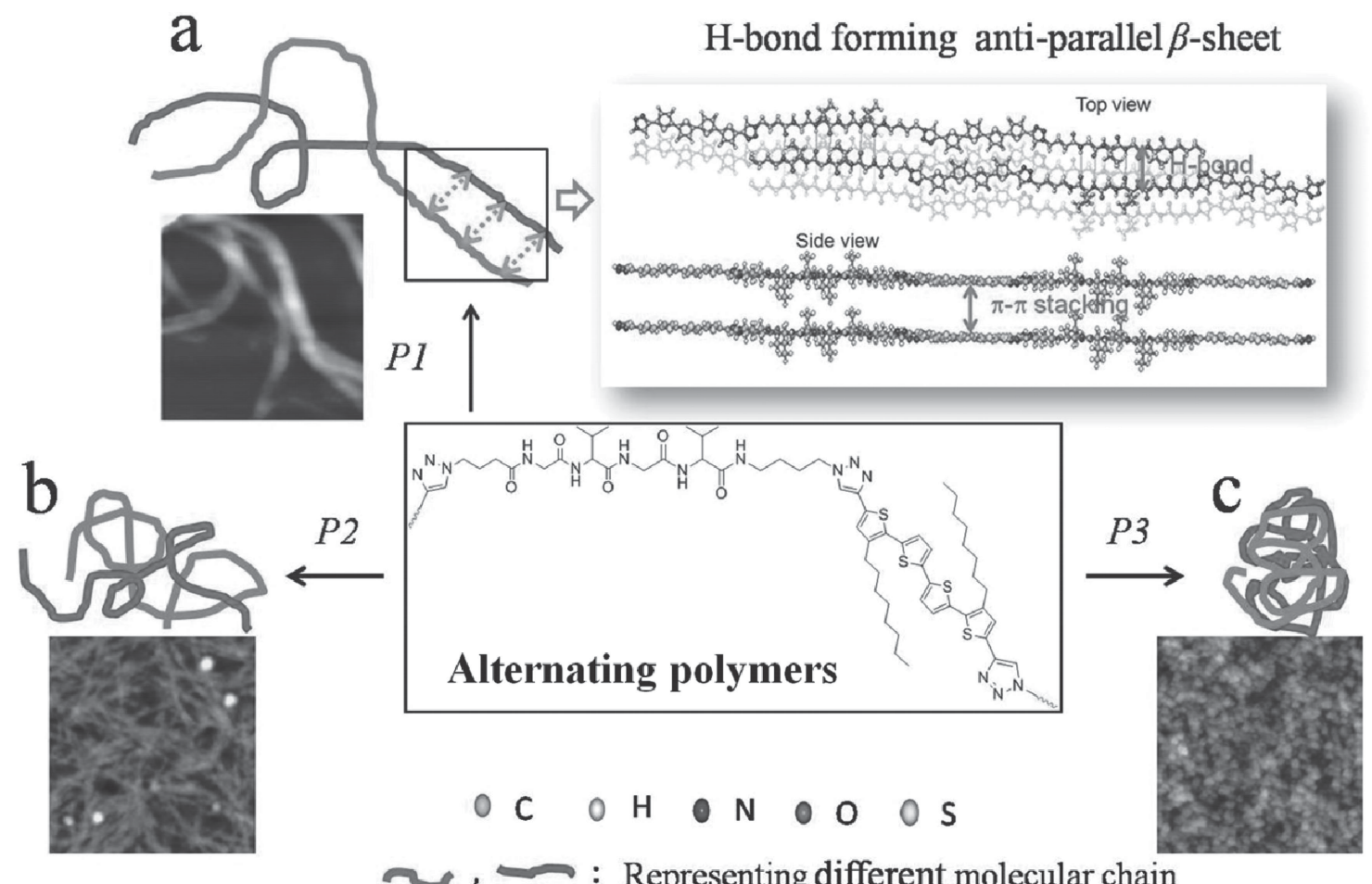

Figure 6. Plausible stacking model for $\mathbf{P}_{1}, \mathbf{P}_{2}$, and $\mathbf{P}_{\mathbf{3}}$ : a) partially ordered-assembly mode of $\mathbf{P}_{1} ;$ b) loosely packed mode of $\mathbf{P}_{2}$; c) closely entangled mode of $\mathbf{P}_{\mathbf{3}}$. 
solid state; iii) P2, the polymer with the molecular weight in between, exhibits a transition state between the other two (Figure 6b).

\section{Conclusion}

Three alternating copolymers P1, P2, and P3 containing tetrapeptides and tetrathiophene segments were prepared by click chemistry. Different from oligopeptideoligothiophene conjugates, these copolymers exhibit a strongly molecular-weight-dependent self-assembly behavior, which was not observed before. Copolymer P1, which has the lowest molecular weight, self-assembles to form a nanofibrillar structure easily. The well-ordered nanostructure attributable to $\beta$-sheet assembly of the oligopeptide segment was confirmed by SEM, AFM, XRD, UV-vis absorption spectra, and FTIR spectroscopy. The ordered oligopeptide region also facilitates the $\pi-\pi$ interaction of the oligothiophene segment, as evidenced by the bathochromic shift of the UV-vis spectrum in the film state. Copolymer P3, which has the highest molecular weight, forms nanoballs. However, no obvious $\beta$-sheet formation was observed. Copolymer P2, with the molecular weight in between, self-assembles into short nanofibers, whereas the assembly of the oligopeptide segments adopts a more-complicated form. Overall, a more-complicated self-assembly behavior of the alternating copolymer of the oligopeptide and oligothiophene is observed compared with that of the oligomer conjugates. At lower molecular weights, when the repeating units in the backbone are fewer than 7 (see Table 2), the copolymer behaves more like oligopeptide-oligothiophene conjugates ${ }^{[6-8,13-18]}$ in which the interchain hydrogen-bonding formation plays a vital role in the self-assembly. The intermolecular hydrogen bonding is weakened with the increase of the molecular weight, and the well-ordered $\beta$-sheets could not be observed when the repeating units increase to roughly 14 (see Table 2). We speculated that since the oligopeptide and oligothiophene segments were linked through a soft spacer, it was possible for the copolymer underwent self-folding, and this process became overwhelming at higher molecular weight. Thus, with the increase of molecular weight, intramolecular hydrogen bonding and $\pi-\pi$ stacking became more important. On the other hand, due to the rigidity of the oligopeptide and oligothiophene segments, and the different effective interaction distance, the intramolecular hydrogen bonding and $\pi-\pi$ stacking might be conflicting and made the self-assembly process more complicated. Moreover, the regio-irregularity of the alternating copolymers might further increase the complexity. This might partially explain why little bathochromic shift in UV-vis spectra was observed for $\mathbf{P 2}$ and P3 in the film state: although normally conjugated oligomers tended to self-assemble to form a more-compact structure in the solid state; however, in polymers, competition between $\pi-\pi$ stacking and hydrogen bonding became more serious with the increase of molecular weight, and might lead to a chaos assembly state, in which the $\pi-\pi$ stacking might not be stronger than that in solution state. In short, the alternating copolymer of oligothiophene and oligopeptides represents a more-complicated system, in which two rigid comonomers with completely different natures guide the self-assembly. Our preliminary results would be helpful in the design of novel copolymers with an adjustable selfassembly ability.

\section{Supporting Information}

Supporting Information is available from the Wiley Online Library or from the author.

Acknowledgements: This work was financially supported by the "100 Talents Program" from the Chinese Academy of Sciences, and the Natural Science Foundation of Shandong Province (ZR2010BZ007). The authors are very grateful to Dr. Shaohua Huang and Ms. Ying Yang for their helpful discussion and technique support in PGSE-NMR analysis for molecular weight determination.

Received: September 3, 2013; Revised: November 22, 2013; Published online: April 4, 2014; DOI: 10.1002/macp.201300563

Keywords: alternating copolymers; molecular weight-dependent assembly; nanostructures; oligopeptides; oligothiophenes

[1] M. J. Winningham, D. Y. Sogah, Macromolecules 1997, 30, 862.

[2] O. Rathore, D. Y. Sogah, Macromolecules 2001, 34, 1477.

[3] O. Rathore, D. Y. Sogah, J. Am. Chem. Soc. 2001, 123, 5231.

[4] H. A. Klok, A. Rosler, G. Gotz, E. Mena-Osteritz, P. Bauerle, Org. Biomol. Chem. 2004, 2, 3541.

[5] R. Matmour, I. De Cat, S. J. George, W. Adriaens, P. Leclere, P. H. H. Bomans, N. A. J. M. Sommerdijk, J. C. Gielen, P. C. M. Christianen, J. T. Heldens, J. C. M. van Hest, D. W. P. M. Lowik, S. De Feyter, E. W. Meijer, A. P. H. J. Schenning, J. Am. Chem. Soc. 2008, 130, 14576.

[6] S. R. Diegelmann, J. M. Gorham, J. D. Tovar, J. Am. Chem. Soc. 2008, 130, 13840.

[7] D. A. Stone, L. Hsu, S. I. Stupp, Soft Matter 2009, 5, 1990.

[8] E. K. Schillinger, E. Mena-Osteritz, J. Hentschel, H. G. Börner, P. Bäuerle, Adv. Mater. 2009, 21, 1562.

[9] A. Schenning, E. W. Meijer, Chem. Commun. 2005, 3245.

[10] M. He, W. Han, J. Ge, Y. Yang, F. Qiu, Z. Lin, Energy Environ. Sci. 2011, 4, 2894.

[11] M. He, F. Qiu, Z. Lin, J. Mater. Chem. 2011, 21, 17039.

[12] O. A. Gus'kova, P. G. Khalatur, P. Bäuerle, A. R. Khokhlov, Chem. Phys. Lett. 2008, 461, 64.

[13] O. A. Gus'kova, E. Schillinger, P. G. Khalatur, P. Bäuerle, A. R. Khokhlov, Polym. Sci. Ser. A. 2009, 51, 430.

[14] O. A. Gus'kova, P. G. Khalatur, A. R. Khokhlov, Macromol. Theory Simul. 2009, 18, 219.

[15] W. W. Tsai, S. L. Li, H. G. Cui, H. Z. Jiang, S. I. Stupp, Tetrahedron 2008, 64, 8504.

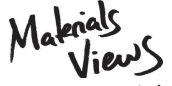

www.MaterialsViews.com 
[16] J. Hentschel, E. Krause, H. G. Börner, J. Am. Chem. Soc. 2006, $128,7722$.

[17] J. Hentschel, M. G. J. ten Cate, H. G. Börner, Macromolecules 2007, 40, 9224.

[18] X. Kong, S. A. Jenekhe, Macromolecules 2004, 37, 8180.

[19] L. Rubatat, X. Kong, S. A. Jenekhe, J. Ruokolainen, M. Hojeij, R. Mezzenga, Macromolecules 2008, 41, 1846.

[20] R. J. Kumar, J. M. MacDonald, T. B. Singh, L. J. Waddington, A. B. Holmes, J. Am. Chem. Soc. 2011, 133, 8564.

[21] X. Wang, R. Gong, Y. Song, M. Li, Y. Mu, Z. Guo, Y. Jiang, X. Wan, W. Jiang, Supramol. Chem. 2013, 25, 842.

[22] Z. X. Guo, Y. B. Song, R. Y. Gong, Y. B. Mu, Y. Jiang, M. Li, X. B. Wan, Supramol. Chem. DOI: 10.1080/10610278.2013.844810.
[23] E. O. Stejskal, J. E. Tanner, J. Chem. Phys. 1965, 42, 288.

[24] P. Stilbs, Prog. Nucl. Magn. Reson. Spectrosc. 1987, 19, 1.

[25] M. Mazarin, S. Viel, B. Allard-Breton, A. Thévand, L. Charles, Anal. Chem. 2006, 78, 2758.

[26] R. Y. Gong, Y. B. Song, Z. X. Guo, M. Li, Y. Jiang, X. B. Wan, Supramol. Chem. 2013, 25, 269.

[27] N. Yamada, K. Ariga, M. Naito, K. Matsubara, E. Koyama, J. Am. Chem. Soc. 1998, 120, 12192.

[28] B. L. Thiel, K. B. Guess, C. Viney, Biopolymers 1997, 41, 703.

[29] B. J. Cafferty, I. Gállego, M. C. Chen, K. I. Farley, R. Eritja, N. V. Hud, J. Am. Chem. Soc. 2013, 135, 2447.

[30] T. B. Yu, J. Z. Bai, Z. B. Guan, Angew. Chem Int. Ed. 2009, 48, 1097. 